\title{
The Fundamental Study of HE-MIP-AES Analysis as Particle-by-Particle Measurement with $\mathrm{SiO}_{2}$ Monodispersed Microsphere
}

\author{
Shingo Saito, Takahisa Tsugoshi, Keiichi Furuya, Yoshiyuki Kudo, *Minako Mishima, \\ *Hisao \\ Takahara, **Tatsuhiko Adachi and * Kazuhiro Sakai \\ Dept. of Appl. Chem. Fac. of Sci., Science University of Tokyo, Kagurazaka, Shinjuku, Tokyo 162, JAPAN, \\ *Particle Analyzer Center, Yokogawa Electric Co., **Ube-Nitto Kasei Co., Ltd.
}

\begin{abstract}
Five types of silica microspheres of uniform size and composition were studied as refractory reference samples for quantification of He-MIP-AES particle analyzer. The cube root of Si emission pulse intensity of individual particles was plotted against their geometrical diameters. A quantitative relationship with the spectrum intensity was found at the highest pulse population of the spectral pulse distribution. However, the distribution of pulse intensity from an uniform fraction was wider than expected and the linear size range was also small between 3.0-6.0 $\mu \mathrm{m}$. On the other hand, each Si emission pulse synchronized within $390 \mu \mathrm{sec}$ with Ti emission pulse in two types of coated silica microspheres and the individual relative emission intensities (Ti vs Si) was almost constant.
\end{abstract}

Keywords: direct analysis of solid samples, microwave induced plasma, silica microsphere

The direct analysis of individual refractory particle is essential for the characterization of environmental, medical aerosol and industrial powders. Various characterization techniques have been developed for powder characterization because powders consist of particles of different size, morphology, composition, and population. Most of the techniques have remained at the level of gross analysis or observation of limited number of individual particles.

Helium microwave induced plasma atomic emission spectroscopy (He-MIP-AES) provides sufficient sensitivity for light elements and halogens, which are important elements for environmental characterization; ordinary analytical methods like AAS, ICP-AES and XRF can not deal with these elements. He-MIP-AES with direct introduction of particles into plasma have been developed by the present authors for elemental speciation and equivalent diameter evaluation of ambient aerosol particles ${ }^{1-3}$. The main difficulty of this method is its quantification for refractory particles which are common in the environment, even though the quantitative linearity of vaporizable latex particles has been confirmed. The reason for this problem is the difficulty of preparing particles of uniform size, morphology and composition, and of measuring emission efficiency. Commercially available glass or silica monodispersed microspheres for LCD spacers often contain void holes, which cause ambiguity of spectrum emission efficiency of a particle in the plasma.

In this study, we investigated the behaviors of atomic emission pulses from individual particles, using silica microspheres (relative size deviation = 1\%) and mono coated silica microspheres with $\mathrm{TiO}_{2}$ and double coated silica microspheres with $\mathrm{TiO}_{2-x^{-}}$ $\mathrm{SiO}_{2}$ prepared by the sol-gel method.

\section{Experimental}

\section{Apparatus}

The apparatus used in this study was a Particle Analyzer PT1000 (Yokogawa Electric Co.); the schematic diagram is shown in Fig. 1 and the operating conditions and detailed instrumentation are shown in Table 1. The plasma is sustained in a $\mathrm{TM}_{010}$ cavity, as described by BEENAKKER ${ }^{4}$ and the analyzing torch consists of a center flow torch; discharge tube (quartz) and center tube (stainless steel). Microwave power of $150 \mathrm{~W}$ at $2.45 \mathrm{GHz}$ was supplied. The total flow rate of $\mathrm{He}$ including aspirating flow was 0.3 $1 / \mathrm{min}$. Four monochrometers (Czerrny-Turner type, $320 \mathrm{~mm}$ ) were connected with optical fibers. In this study, $\mathrm{He}+0.1 \% \mathrm{O}_{2}$ was used. 


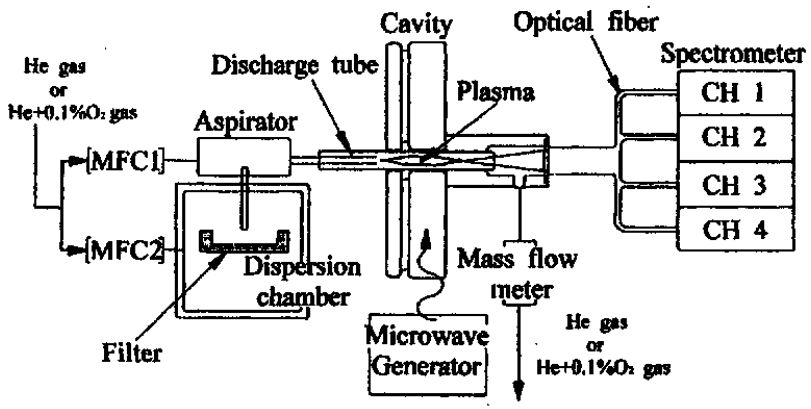

Fig. 1 Schematic diagram of Particle Analyzer PT1000

Table 1 Instrumentation and operating conditions

\begin{tabular}{cc}
\hline Plasma system & \\
\hline Cavity & TM $_{010}$, BeENAKKRR type \\
Generator & $150 \mathrm{~W}, 2.45 \mathrm{GHz}$ \\
Plasma gas & $\mathrm{He}+0.1 \% \mathrm{O}_{2}$ \\
Flow rate & $0.3 \mathrm{ml} / \mathrm{min}$ \\
\hline Optical system & \\
\hline Monochrometer & Czerrny-turner, 320 mm \\
\hline
\end{tabular}

\section{Samples}

For the reference materials, as a series of silica monodispersed microspheres (HIPRESICA, UbeNitto Kasei Co. Ltd.) for spacer materials in liquid crystal devices was selected from among test samples due to uniform size and density. The size and relative standard deviations are shown in Table 2.

Table 2 Relative standard deviation to the each diameter of silica monodispared microspheres

\begin{tabular}{cccccc}
\hline $\begin{array}{c}\text { Diameter } \\
\text { (um) }\end{array}$ & 3.0 & 4.7 & 6.0 & 8.9 & 10.3 \\
\hline $\begin{array}{c}\text { R.S.D } \\
\text { (\%) }\end{array}$ & 0.77 & 1.13 & 0.93 & 0.85 & 0.65 \\
\hline
\end{tabular}

As these particles are synthesized by the sol-gel method, size deviations are small and the particles do not have any void holes, which were often found in fused silica or glass microspheres. Two types of $\mathrm{TiO}_{2}$ coated silica microspheres were also prepared for the observation of vaporization behavior and elemental matrix effect. Silica microspheres of $4.9 \mu \mathrm{m}$ in diameter were coated with $0.2 \mu \mathrm{m}$ of $\mathrm{TiO}_{2}$ and double oated microspheres were prepared with $\mathrm{TiO}_{2-x}$ $(0.2 \mu \mathrm{m})-\mathrm{SiO}_{2}(0.1 \mu \mathrm{m})$ on the same silica microspheres of $4.9 \mu \mathrm{m}$.

\section{Procedure}

Sample particles were collected on a filter by means of a low volume air sampler. The filter was set on a filter holder in the disperser chamber. The particles were introduced into the plasma in turn by an aspiration nozzle with $\mathrm{He}$ carrier gas. The condensed particles were released in the sonic velocity region of the aspirator and were introduced into the plasma individually. The emission pulse data were processed to calculate: 1) the pulse population against the cube root of $\mathrm{Si}$ emission intensity, 2) coincidence behavior between $\mathrm{Si}$ and $\mathrm{Ti}$ from the coated microspheres both in population and intensity and 3) calibration curve using Si emission intensities at the highest pulse population from five types of $\mathrm{SiO}_{2}$ microsphere with different diameters.

\section{Result and discussion}

Comparison between $\mathrm{TiO}_{2}$ coated and not $\mathrm{TiO}_{2}$ coated $\mathrm{SiO}_{2}$ microspheres

The quantities of $\mathrm{Si}$ in $\mathrm{SiO}_{2}$ microspheres of 4.7 $\mu \mathrm{m}$ in diameter and $\mathrm{TiO}_{2}$ coated $\mathrm{SiO}_{2}$ were the same. Fig. 2 shows the comparison of $\mathrm{Si}$ emission pulse population against the cube root of its emission intensity. The blank bars show the Si emission pulse population. The black bars show those in coincidence with Ti pulses. Both distributions are the same but widely scattered in spite of their small size distribution.

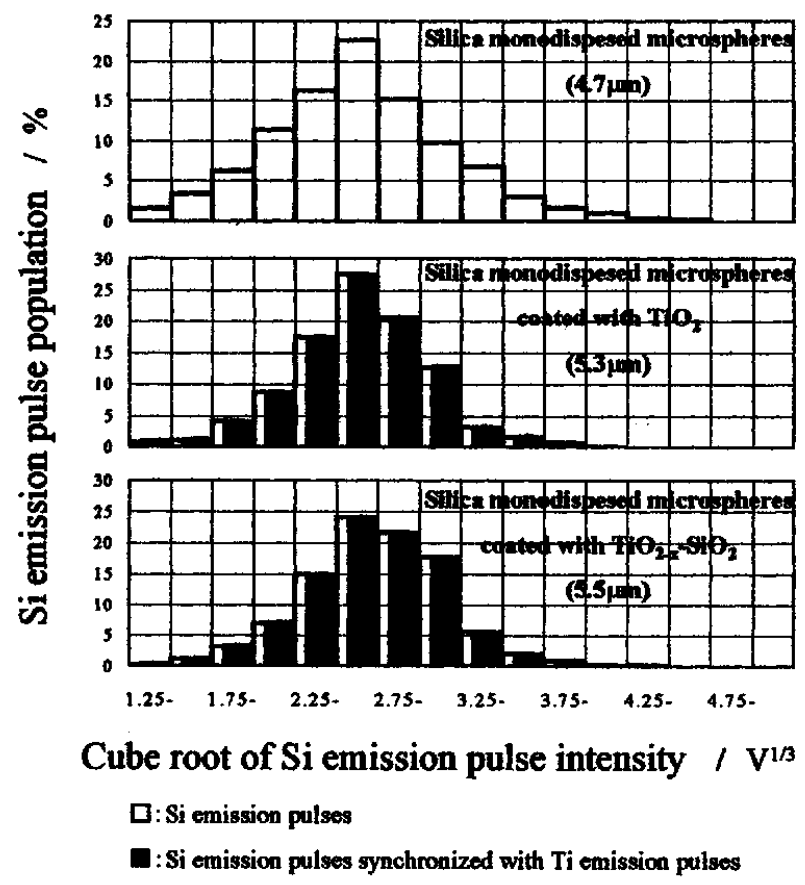

Fig. 2 Comparison of Si emission pulse population against cube root of its emission intensity

\section{Rrelative emission intensity between Ti and Si}

When particles with uniform composition are activated uniformly, the relative emission intensity between two compositional elements should be constant. Fig. 3 shows a plot of Ti emission intensity against $\mathrm{Si}$ emission intensity. 


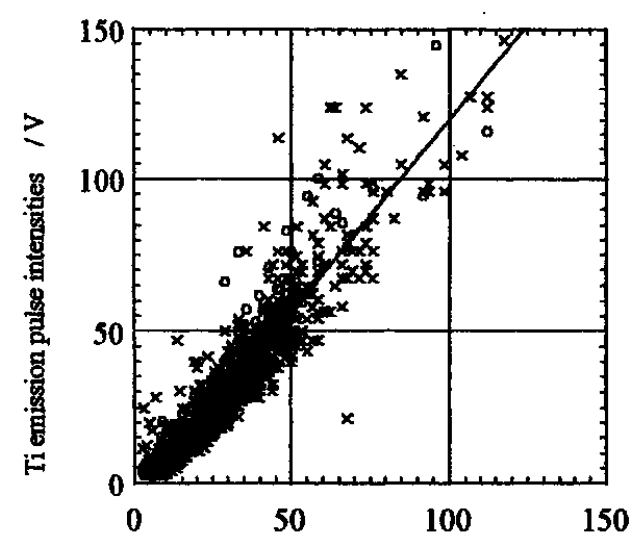

Si emission pulse intensities /V

$\mathrm{O}: \mathrm{SiO}_{2}$ monodispersed microsphere coated with $\mathrm{TiO}_{2}$ $\times: \mathrm{SiO}_{2}$ monodispersed microsphere coated with $\mathrm{SiO}_{2}-\mathrm{TiO}_{2-\mathrm{X}}$

Fig. 3 Relative emission intensity between $\mathrm{Ti}$ and $\mathrm{Si}$

There is a linear relationship between $\mathrm{Ti}$ and $\mathrm{Si}$, which means a constant relative emission intensity irrespective of their scattered values. Therefore Si emission pulses represent individual particle emission but the distribution of pulse height shows unstable emission efficiency of refractory oxide particles

\section{Dynamic behavior of Si and Ti emission pulses}

Fig. 4 shows the dynamic behavior of $\mathrm{Si}$ and $\mathrm{Ti}$ emission pulses observed with an oscilloscope.

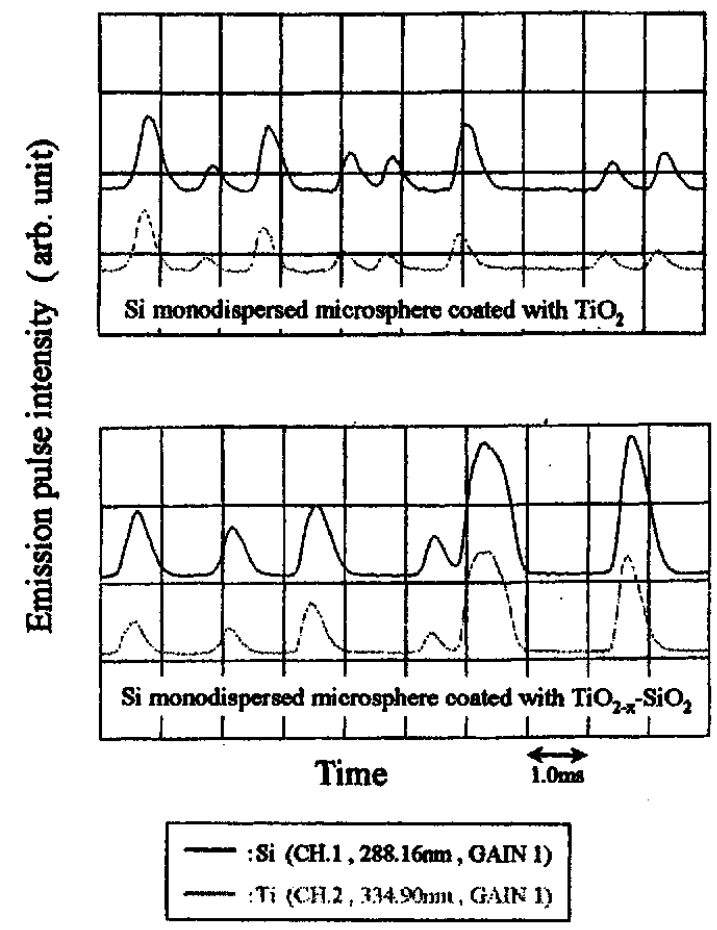

Fig. 4 Dynamic behavior of $\mathrm{Si}$ and $\mathrm{Ti}$ emission pulses
The Ti emission pulse precedes by about $100 \mu \mathrm{sec}$ the $\mathrm{Si}$ emission pulse for the two different coated samples. This indicates that all particles vaporized instantaneously within about $100 \mu \mathrm{sec}$ with unstable emission efficiency, which causing the scattered peak height. This has also been reported in the heat vaporization introduction method ${ }^{5}$.

Si emission pulse height with highest pulse population

Three types of $\mathrm{SiO}_{2}$ microsphere with and without $\mathrm{TiO}_{2}$ coating gave the same $\mathrm{Si}$ emission pulse height with highest population. A plot of the emission pulse distribution for five types of $\mathrm{SiO}_{2}$ microsphere of different size is shown in Fig. 5.

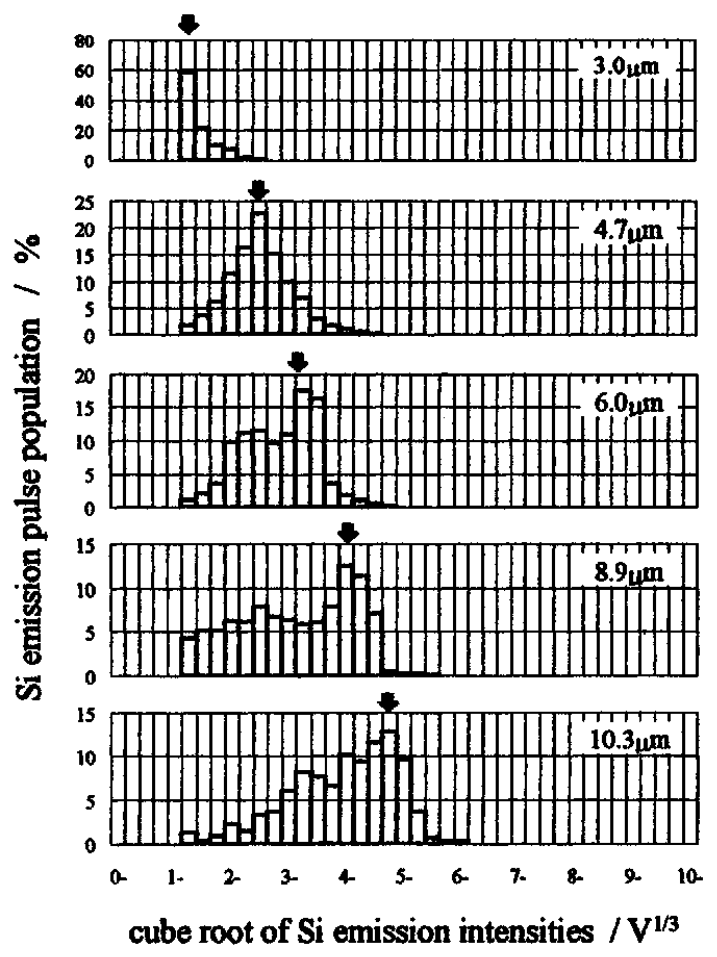

Fig. 5 Plot of emission pulse distribution for five types of $\mathrm{SiO}_{2}$ microsphere with different size

Although the distributions are fairly scattered, the pulse height with highest population increased with the increase of size or quantity. Fig. 6 shows a calibration curve of $\mathrm{Si}$ in the diameter range of 3.0$10.0 \mu \mathrm{m}$. The linear range of the curve was so small and saturated in the larger size range. The same tendency was also observed in a study of ICP-AES with the slurry introduction method ${ }^{6.7}$. This can be explained by the decrease of vaporization and atomization efficiencies as the diameter of $\mathrm{SiO}_{2}$ particles increases. However, the vaporization efficiency should be excluded because the dynamic behaviors of $\mathrm{Si}$ and $\mathrm{Ti}$ were the same as explained in the preceding section. 


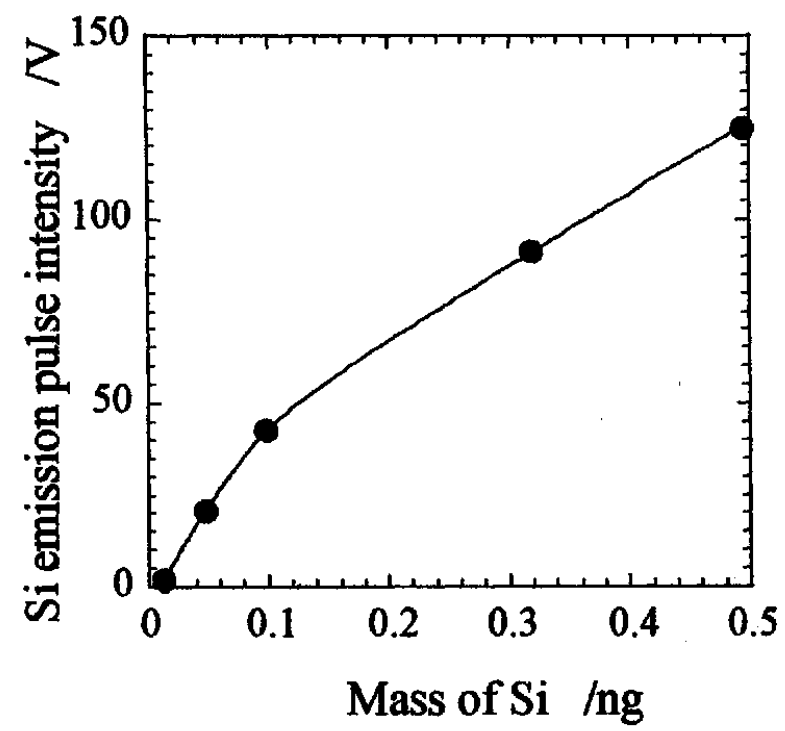

Fig. 6 Calibration curve of $\mathrm{Si}$ in the diameter range of

$$
\text { 3.0-10.0 } \mu \mathrm{m}
$$

Quantitative estimation of particle-by-particle analysis for refractory materials, it is possible for monodispersed particles using pulse height with highest population. However, the main problem for further samples might be the scattered emission efficiency of individual particles in the plasma. Improvement of the efficiency should make the HeMIP-AES particle analyzer a more powerful tool.

\section{References}

1. H. Takahara, Ultra Clean Technology, 5, 4 (1993) [in Japanese]

2. H. Takahara, Earozoru Kenkyu, 11, 26 (1996) [in Japanese]

3. E.M.S. Frame, Y. Takamatsu and T. Suzuki, Spectroscopy, 11, 17 (1996)

4. C.I.M. Beenakker: Spectrochim. Acta, 32B, 173 (1978)

5. J.M. Ren and E.D. Salin, Spectrochim. Acta, 49B, 567 (1994)

6. B. Raeymaeker, T. Graule, J.A.C. Broekaert, F. Adams and P. Tschöpel, Spectrochim. Acta, 43B, 923 (1988)

7. L. Ebdon, M.E. Foulkes and S. Hill, J.Anal.At.Spectrom., 5, 67(1990) 